\title{
A CONTRIBUIÇÃO DA EXTENSÃO UNIVERSITÁRIA NA FORMAÇÃO ACADÊMICA: DESAFIOS E PERSPECTIVAS
}

\author{
THE CONTRIBUTION OF \\ UNIVERSITY EXTENSION \\ IN ACADEMIC EDUCACION: \\ CHALLENGES AND PROSPECTS
}

RN / PE - BRASIL

\author{
Mayra Rodrigues Fernandes Ribeiro* \\ Verônica Maria de Araújo Pontes ${ }^{* *}$ \\ Etevaldo Almeida Silva ${ }^{* * *}$
}

\section{RESUMO}

Este estudo intenciona perceber como o professor expressa a natureza da atividade de extensão em seus projetos, usando como parâmetro de análise a aproximação e o distanciamento da potência da extensão universitária como dispositivo formativo inspirado na práxis. Como campo empírico, foram utilizadas propostas de ações extensionistas apresentadas por professores no cenário formativo da Universidade do Estado do Rio Grande do Norte, por meio do edital de carga horária do ano de 2016. Foram selecionadas $14 \%$ das propostas aprovadas em 2016, nas quais analisaram-se os itens: indissociabilidade entre ensino-pesquisa-extensão; natureza e avaliação da extensão. Constatou-se a importância de um diálogo formativo que viabilize a discussão do conceito de extensão na perspectiva de ampliação dos sentidos, para uma (trans) formação em devir de uma postura docente implicada com a formação dialógica, por meio de saberes plurais que perpassam a vida dentro fora da Universidade.

Palavras chave: extensão universitária; epistemologia; formação humana.

\section{ABSTRACT}

This study aims at analysing how teachers express the nature of the extension activity in their projects, using the approaching and distancing of the university extension potential as an education device inspired in the praxis as a parameter of analysis. The empirical field comprised the extension actions proposed by teachers in the education scenery of the State University of Rio Grande do Norte, through the workload notice for $2016.14 \%$ of the proposals approved in 2016 were selected, in which the items below were analysed: the inextricable connection between teaching-research-extension and the extension nature and evaluation. The importance of a formative dialogue which enables the discussion of the concept of

\footnotetext{
* Professora da Universidade do Estado do Rio Grande do Norte (UERN), RN - Brasil. E-mail: mayra.rfr@gmail.com

** Professora da Universidade do Estado do Rio Grande do Norte (UERN), RN - Brasil. E-mail: veronicauern@gmail.com

*** Professor da Universidade do Estado do Rio Grande do Norte (UERN), RN - Brasil. Aluno de Doutorado da Universidade Federal de Pernambuco (UFPE), PE - Brasil. E-mail: etevaldoalmeidasilva@gmail.com
} 
extension in the perspective of broadening senses, for some transformation in the evolution of a teaching posture with dialogical education, through plural knowledge that permeate the University insideoutside.

Keywords: university extension; epistemology; human education.

\section{Introduçáo}

As discussóes político-acadêmicas sobre a função formativa e social da Universidade vêm se transformando qualitativamente e quantitativamente no final do século XX e mais preponderantemente no século XXI, principalmente no que se refere à noção de ciência, produção de conhecimento e acesso ao ensino superior. De lócus único de produção de conhecimento ancorado em paradigmas positivistas e cartesianos, a Universidade vai, gradativamente, se reconfigurando em lugar de polifonia e de possibilidades de "fazer ciência com um rigor outro" (GALLEFI, 2009; MACEDO, 2009),que consiste em problematizarmosos excessos iluministas que reduzirem, ou até mesmo desconsiderarem, as epistemologias das práticas, os saberes fazeres plurais produzidos pelos atores no cotidiano.

Nesse cenário de transformação da Universidade, podemos situaras mudanças da natureza conceitual e prática da extensão universitária expressa por várias correntes de pensamento, que a coloca em momentos de tessitura de políticas e açóes que passam pela configuração de lutas internas, espaço de resistência e possibilidade de militância, desencadeadoras de um processo de institucionalização e fortalecimento da extensão no âmbito da Universidade e da sociedade.

Nesse veio, afirmamos que a extensão universitária, entendida como parte indispensável do tripé formativo acadêmico-profissional, sempre precisou alavancar lutas políticas que viabilizassem a sua consolidaçáo ao lado do ensino e da pesquisa.Como exemplo dessas lutas e conquistas, podemos exemplificar a equivalênciada carga horáriade extensão a de projetos de pesquisa; o financiamento por meio de Edital nacional, como o PROEXT; a valorização da extensão como lócus que transita epistemologicamente pela/na práxis, ou seja, os saberes teóricos articulados aos saberes da ação dos professores, alunos e comunidade externa, situados em contextos formativos das/nas experiências aprendentes dentro fora da Universidade estáo em processos de ressignificaçóes permanentes (RIBEIRO, 2015, grifos nossos).

Com essas premissas, entendemos ser de grande relevância para o pensar político-epistemológicometodológico da extensáo deslocá-la para o centro do debate epistemológico, entendendo-a como possibilidade de inspiração de fazeres fazeres(trans)formadores do ensino e da pesquisa. A extensão com a qual nos implicamosé entendida como atividade formadora viabilizadora de diálogos com saberes plurais, fundada na experiência e reflexáo vivenciadas nos diversos espaços socioculturais, nos quais as referências e intencionalidades formativas produzem sentidos também diversos e plurais.

Assim, nos formamos enquanto formamos por meio de uma política de sentidos produzidos pelos praticantes culturais ${ }^{1}$ que atuam no cotidiano, em diversos espaços de aprendizagem, ampliados e ressignificados pelas/nas atividades de extensão.

Imbricados de razáo-emoção-desejo, intencionamos com este estudo perceber como o professor extensionista expressa a natureza da atividade de extensão em seus projetos, tendo como parâmetro de análise a aproximação e o distanciamento da potência da extensão universitária como dispositivo formativo favorável ao exercício acadêmico-profissional, inspirado na práxis, na ação reflexiva e transformadora dos

1 A noção de praticante utilizada neste artigo tem inspiração nos estudos de Certeau (2012, p.41), ao se referir ao homem comum, "consumidor de produtos", que ao produzir táticas anônimas nas artes de fazer, se reapropria do cotidiano da vida numa sociedade de consumo. E essas "maneiras de fazer" "constituem as mil práticas pelas quais os usuários se apropriam do espaço organizado pelas técnicas da produção cultural". 
sujeitos envolvidos. Utilizamos a noçáo de dispositivo com base em Ardoino (1998, p.80) para o qual consiste em "uma organização de meios materiais e/ou intelectuais, fazendo parte de uma estratégia de conhecimento de um objeto".

Pensar a atividade de extensáo como dispositivo consiste em perceber a sua potência formativa acadêmica-profissional, retroalimentadora da teoria e da prática, ou seja, uma formação como práxis. Nesse movimento, a teoria ilumina a prática, sendo a primeirares significada pela prática, e esta, transformada em função da reflexão na ação e sobre a reflexáo na ação.

Esse entendimento epistemológico nos leva a questionarmos: quais sentidos professores, alunos e comunidade externa atribuem às atividades de extensão? Como os professores expressam as perspectivas epistemológicas coerentes com a natureza da atividade extensionista em seus projetos de extensão? Qual formação humana-profissional tem se aproximado dos seus saberes fazeres na relaçáo formativa dentro fora da universidade?

Essas questóes, enredadas dos sentidos epistemológicos que consubstanciam a natureza da atividade extensionista na Universidade, são o mote para avançarmos na tessitura deste artigo, procurando identificar como o professor extensionista expressa a natureza dessa atividade em seus projetos de extensão, tendo como parâmetro de análise a aproximação e o distanciamento da potência da extensão Universitária, como dispositivo formativo favorável ao exercício acadêmico-profissional inspirado na práxis, na açẫo reflexiva e transformadora dos sujeitos envolvidos.

O estudo teve como campo empírico as propostas de açóes extensionistas apresentadas por professores no cenário formativo da Universidade do Estado do Rio Grande do Norte,UERN, por meio do edital de carga horária 2016.1 e 2016.2, nas quaisanalisamos os itens relacionados à indissociabilidade entre ensino-pesquisaextensão;natureza e avaliaçãoda extensão apresentadas nos projetos.

Em nossas redes de conhecimento, trazemos como inspiraçáo epistemológica o conceito de extensão expresso pelo FORPROEX (2013), para o qual "a Extensão Universitária é um processo interdisciplinar, educativo, cultural, científico e político que promove a interaçấo transformadora entre Universidade e outros setores da sociedade, em uma relação indissociável com a pesquisa e o ensino". Esses espaçostemposformativos precisam ser percebidos e olhados em uma perspectiva complexa, nos quais saberes plurais e heterogêneos se entrecruzam, dialogam em meio a tensóes, negociaçóes de sentidos e produção de significados.

\section{Método}

A Universidade do Estado do Rio Grande do Norte vem progressivamente ampliando a sua política de extensão, fortalecendo e estimulando os departamentos acadêmicos a desenvolverem a formaçáo acadêmico-profissional com base no princípio da indissociabilidade entre ensino-pesquisa-extensão. Nesse sentido, lança-se anualmente um edital de carga horária de extensão, no qual os professores apresentam suas propostas para serem submetidas à comissão de extensão. Esta comissão é formada por professores dos diferentes departamentos da UERN e de professores das Diretorias da Pró-Reitoria de Extensão, tendo na coordenação o Pró-Reitor de Extensão. 
Para o ano de 2016, foram apresentadas 76 propostas e aprovadas 73 , tendo como principais parâmetros de avaliação a natureza da extensão expressa no conceito do fórum; o princípio da indissociabilidade entre ensino pesquisa e extensáo, e a avaliaçáo da açáo na perspectiva do público externo à IES e o público interno.

O processo de avaliação das Propostas de Extensão submetidos ao edital de carga horária possibilitou, tanto aos professores inseridos na PROEX como aos professores membros da extensão, externar a necessidade de se repensarem critérios de avaliaçáo que contribuam com o aperfeiçoamento dessas práticas e com a qualidade na elaboraçáa das propostas de extensão, uma vez que, tanto quem elabora como quem avalia fica mais a mercê do entendimento subjetivo significado pela rede de conhecimento de cada um. Com isso, não queremos dizer que é possível objetivar uma avaliação nos critérios das ciências "duras", mas construir critérios que venham a valorar aspectos importantes na tessitura desses projetos e na elaboraçáo dos pareceres avaliativos.

Implicados nesse cenário de tensionamento sobre o entendimento da extensão e seus desdobramentos, nos vimos questionando sobre: o que estamos entendendo sobre o diálogo interdisciplinar entre educaçáo-cultura-conhecimento científico e político, expresso no conceito do fórum? Como essa relação tem sido apresentada nos projetos de extensão da UERN? E a relação entre ensino, pesquisa e extensão, como tem sido entendida por quem elabora e por quem avalia as açóesde extensão?De que pesquisa estamos falando? Para realizar extensão precisa ser pesquisador? Pesquisa como olhar curioso e reflexivo no ato da ação de extensão, fomentando as discussóes no ensino? Pesquisa como diagnóstico a priori como condição para proposição de açôes de extensão?

Com o propósito de ampliarmos a discussáo e nos aproximamos do entendimento dessas questóes, selecionamos $14 \%$ das açóes aprovadas no edital, o que correspondeu a 10açôes de extensão. A escolha das açôes foi aleatória, por meio do acesso ao Sigproj/ UERN. A pesquisa que realizamos teve uma preocupação quantitativa apenas no que diz respeito ao que consideramos ser representativo para o estudo.

No entanto, a ênfase na pesquisa qualitativa justifica-se em função da perspectiva epistemológica em que nos inspiramos, e que nos coloca no lugar de olharmos para a tessitura das açóes, apresentadas como narrativas, que expressam redes de conhecimentos (ALVES, 2008) de quem os elabora, não cabendo binarismos de certo ou errado, ou, ainda, enquadramentos nas noçóes que nos inspiram.

Com esse pensamento, nos aproximamos da pesquisa-formação (MACEDO, 2009; JOSSO, 2010; FREIRE, 1998) com perspectiva epistemológica multirreferencial (ARDOINO, 1998; MACEDO, 2009), para a qual o conhecimento se tece por meio de diálogos plurais, em permanente processo de auto-formação e formação.Com isso, entendemos estar contribuindo com uma prática formativa que rompe com o paradigma preescritivo e aposta na reflexividade do sujeito e na sua capacidade de permanente (trans) formação de si e dos lugares onde interage (PASSEGI; SOUZA, 2008).

As 10 açóes de extensãoselecionadas serão denominadas atividades extensionistas $\mathrm{AE}$, seguidas de números em ordem crescente. Pela escolha aleatória, encontramos ações vinculadas aos seis Campus da UERN, conforme Quadro I. 


\section{Quadro I - Açóes extensionistas - edital carga horária 2016}

\begin{tabular}{|l|l|l|l|l|}
\hline Açáo de Extensão & Tipo da açáo & Área Temática & Departamento de Vinculação & $\begin{array}{l}\text { Titulaçáo do } \\
\text { coordenador }\end{array}$ \\
\hline AEI & Curso & Educação & Informática/Natal & Doutor \\
\hline AEII & Projeto & Educação & Enfermagem/Pau dos Ferros & Doutor \\
\hline AEIII & Projeto & Saúde & Odontologia/Caicó & Mestre \\
\hline AEIV & Programa & Saúde & Educação Física/Mossoró & Mestre \\
\hline AEV & Projeto & Educação & Filosofia/Mossoró & Doutor \\
\hline AEVI & Projeto & Saúde & Odontologia/Caicó & Doutor \\
\hline AEVII & Projeto & Educação & Informática/Mossoró & Mestre \\
\hline AEVIII & Curso & Trabalho & Ciências Contábeis/ Patu & Mestre \\
\hline AEIX & Projeto & Comunicação & Comunicaçáo Social/Mossoró & Doutor \\
\hline AEX & Projeto & $\begin{array}{l}\text { Direitos humanos } \\
\text { e justiça }\end{array}$ & Direito/Natal & Mestre \\
\hline
\end{tabular}

A elaboração das açôes extensionistas seguem o formulário do Sigproj /UERN, no qual está proposto alguns itens, como: fundamentação teórica da ação proposta; relação entre ensino, pesquisa e extensão, o que pressupóe um entendimento sobre a definição explicitada no fórum, para a qual a interdisciplinaridade, interação e transformação formam a trama de sentidos da natureza extensionista na Universidade; e, ainda, a avaliação da ação e dos sujeitos envolvidos.

Considerando que a avaliação do item fundamentação teórica não pode se dar com base nas perspectivas epistemológicas das redes do avaliador, uma vez que esta não pode ser tida como o parâmetro de "verdade", da "melhor forma" de compreender o conhecimento, não nos debruçamos sobre esse ponto e ressaltamos a importância de ser considerado apenas no que diz respeito à consistência dos argumentos e à organização das ideias de sustentação da ação proposta.

Optamos por problematizar as noçóes de extensão e a ideia de relação da extensão com a pesquisa,o ensino e a avaliação apresentados nas propostas. Como procedimento metodológico, selecionamos, das narrativas apresentadas, termos que expressam sentidos relacionados aos itens em destaque nos Quadros II e III, conforme podemos observar:

\section{Quadro II - Noçóes de Extensão apresentadas nas açóes de extensáo - Edital carga horária/2016}

continua

\begin{tabular}{|l|l|l|l|}
\hline $\begin{array}{c}\text { Açáo de } \\
\text { Extensáo }\end{array}$ & $\begin{array}{c}\text { Tipo da } \\
\text { açáo }\end{array}$ & \multicolumn{1}{|c|}{ Entendimento de Extensáo } & \multicolumn{1}{c|}{$\begin{array}{c}\text { Relaçáo da extensáo com o ensino e a } \\
\text { pesquisa }\end{array}$} \\
\hline AEI & Curso & - Intervir sobre uma dada realidade & $\begin{array}{l}\text { - Pesquisa: o aluno deve realizar pesquisas } \\
\text { sobre assuntos relacionados ao conteúdo do } \\
\text { curso; } \\
\text { - Ensino: necessidade de o aluno aprender e } \\
\text { aprofundar conteúdos do Curso; } \\
\text { - Extensão: momento de compartilhar o } \\
\text { conhecimento adquirido na graduaçáo. }\end{array}$ \\
\hline AEII & Projeto & $\begin{array}{l}\text { - Fomentadora de mudanças na } \\
\text { realidade dos envolvidos }\end{array}$ & $\begin{array}{l}\text { - Extensão como campo de pesquisa; } \\
\text {-Fomentadora de mudanças nos cenários de } \\
\text { formação das instituiçóes envolvidas. }\end{array}$ \\
\hline
\end{tabular}




\section{Quadro II - Noçóes de Extensão apresentadas nas açóes de extensão - Edital carga horária/2016}

conclusão

\begin{tabular}{|c|c|c|c|}
\hline $\begin{array}{c}\text { Açáa de } \\
\text { Extensáo }\end{array}$ & $\begin{array}{l}\text { Tipo da } \\
\text { ação }\end{array}$ & Entendimento de Extensão & $\begin{array}{c}\text { Relaçáo da extensão com o ensino e a } \\
\text { pesquisa }\end{array}$ \\
\hline AEIII & Projeto & $\begin{array}{l}\text { - Prestaçáo de serviço à } \\
\text { comunidade e retroalimentadora } \\
\text { do ensino e da pesquisa. }\end{array}$ & $\begin{array}{l}\text {-A extensão possibilita articulaçáo no } \\
\text { desenvolvimento da visão crítica científica } \\
\text { dos alunos e proporciona leituras de artigos } \\
\text { com ênfase na avaliação de sua metodologia } \\
\text { de pesquisa; } \\
\text { - Aguçar o interesse sobre assuntos inerentes } \\
\text { à pesquisa científica, combase nos resultados } \\
\text { obtidos no projetode extensão. }\end{array}$ \\
\hline AEIV & Programa & $\begin{array}{l}\text { - Momento de aplicação do } \\
\text { conhecimento via interação } \\
\text { universidade e sociedade }\end{array}$ & $\begin{array}{l}\text {-Extensão como forma de revitalizar o ensino } \\
\text { e gerar questôes de pesquisa(a experiência } \\
\text { é levada para a sala de aula, enriquecendo } \\
\text { a discussão e aumentando o significado do } \\
\text { conteúdo teórico). }\end{array}$ \\
\hline AEV & Projeto & $\begin{array}{l}\text { - Atividade de ensino viabilizadora } \\
\text { de uma integralidade na formação } \\
\text { e no maior acesso ao tripé } \\
\text { acadêmico: ensino- pesquisa- } \\
\text { extensáo }\end{array}$ & - \\
\hline AEVI & Projeto & $\begin{array}{l}\text { - Atividade retroalimentadora do } \\
\text { ensino e beneficiadora do social } \\
\text { (público atendido). }\end{array}$ & $\begin{array}{l}\text { - Ensino: discute as demandas surgidas na } \\
\text { extensão; } \\
\text { Extensão: aguçadora da visão crítica dos } \\
\text { alunos alimentando a pesquisa e o ensino. }\end{array}$ \\
\hline AEVII & Projeto & $\begin{array}{l}\text { - Construção de conhecimento } \\
\text { coletivo do grupo. }\end{array}$ & $\begin{array}{l}\text { - Vivência das práticas de pesquisa, ensino } \\
\text { e trabalho, por parte do grupo que compóe } \\
\text { o projeto, com membros da sociedade } \\
\text { produz um aprendizado prático para a vida } \\
\text { estudantil; } \\
\text { - A prática como fortalecedora dos conceitos } \\
\text { estudados em sala de aula. }\end{array}$ \\
\hline AEVIII & Curso & $\begin{array}{l}\text { - Extensão como espaço de } \\
\text { aplicabilidade da teoria estudada } \\
\text { na Universidade. }\end{array}$ & $\begin{array}{l}\text {-A relaçáo ensino, pesquisa e extensão ocorre } \\
\text { através da vivência da equipe de trabalho na } \\
\text { aplicaçáo prática das teorias estudadas em } \\
\text { sala de aula, junto aos participantes }\end{array}$ \\
\hline AEIX & Projeto & $\begin{array}{l}\text { - Extensão como momento de } \\
\text { intervenção da Universidade } \\
\text { através do ensino. }\end{array}$ & $\begin{array}{l}\text { - A pesquisa comparece de modo indireto } \\
\text { (pesquisa bibliográfica como campo de } \\
\text { análise contínuo, necessária para lidar com o } \\
\text { ensino necessário nas açôes do projeto; } \\
\text { - A extensão gera discussóes sobre o tema, } \\
\text { que requer constante atualização. }\end{array}$ \\
\hline AEX & Projeto & $\begin{array}{l}\text { - Diálogo entre Universidade e } \\
\text { Sociedade; } \\
\text { - Experiência autêntica entre teoria } \\
\text { e prática }\end{array}$ & $\begin{array}{l}\text { - Os conteúdos trabalhados em sala, nas } \\
\text { várias disciplinas, serão desdobrados na } \\
\text { prática extensionista, e estas serão } \\
\text { substrato para pesquisas. }\end{array}$ \\
\hline
\end{tabular}




\section{Quadro III - Avaliaçáo apresentada nas açóes de extensáo - Edital carga horária/2016}

\begin{tabular}{|c|c|c|c|}
\hline $\begin{array}{l}\text { Açáo de } \\
\text { Extensáo }\end{array}$ & $\begin{array}{l}\text { Tipo da } \\
\text { açáo }\end{array}$ & A avaliaçáo & Instrumentos avaliativos \\
\hline AEI & Curso & $\begin{array}{l}\text { - Continuamente para o êxito no processo } \\
\text { de ensino-aprendizagem. } \\
\text { - Se houve impacto no rendimento dos } \\
\text { alunos participantes na aprendizagem dos } \\
\text { conteúdos escolares. }\end{array}$ & $\begin{array}{l}\text { - Questionário } \\
\text { - Discussão } \\
\text { - Atividades } \\
\text { - Averiguação }\end{array}$ \\
\hline AEII & Projeto & $\begin{array}{l}\text { - As estratégias de avaliação são dinâmicas } \\
\text { e processuais } \\
\text { - Feedback } \\
\text { - Verificação de mudanças no processo }\end{array}$ & $\begin{array}{l}\text { - Questionários } \\
\text { - Relatórios } \\
\text { - Artigos científicos }\end{array}$ \\
\hline AEIII & Projeto & $\begin{array}{l}\text { - Muito geral, compreendendo apenas as } \\
\text { informaçóes do projeto }\end{array}$ & - Questionário \\
\hline AEIV & Programa & $\begin{array}{l}\text { - Verificaçáo se o programa está sendo de } \\
\text { acordo com o prognóstico proposto e se } \\
\text { foi atingido. } \\
\text { - Envolvimento da equipe. } \\
\text { - Nível de satisfação atingido. } \\
\text { - Impacto na qualidade de vida } \\
\text { - Soluçáo de problemas para os principais } \\
\text { problemas apresentados. } \\
\text { - Quantitativa e qualitativa. } \\
\text { - A contribuição do programa em } \\
\text { atividades de ensino e pesquisa. }\end{array}$ & $\begin{array}{l}\text { - Questionário } \\
\text { - Relatório } \\
\text { - Assiduidade, pontualidade } \\
\text { - Preparação das aulas } \\
\text { - Criatividade e cumprimento } \\
\text { - Testes } \\
\text { - Reunióes }\end{array}$ \\
\hline $\mathrm{AEV}$ & Projeto & $\begin{array}{l}\text { - Desenvolvimento da capacidade de } \\
\text { compreensáo }\end{array}$ & $\begin{array}{l}\text { - Tradução e publicação de dois } \\
\text { artigos. } \\
\text { - Frequência e participação nas } \\
\text { atividades } \\
\text { - Resultado da tradução }\end{array}$ \\
\hline AEVI & Projeto & - Informaçôes sobre o referido projeto. & - Questionário \\
\hline AEVII & Projeto & $\begin{array}{l}\text { - Conhecer como o público vê o projeto, e } \\
\text { como este pode ser melhorado. }\end{array}$ & $\begin{array}{l}\text { - Questionários } \\
\text { - Quadro de sugestóes } \\
\text { - Formulários } \\
\text { - Entrevista coletiva }\end{array}$ \\
\hline AEVIII & Curso & $\begin{array}{l}\text { - Para correçáo de falhas e reforço dos } \\
\text { aspectos positivos. }\end{array}$ & $\begin{array}{l}\text { - Questionário } \\
\text { - Reunião }\end{array}$ \\
\hline AEIX & Projeto & - Verificação dos objetivos atingidos. & $\begin{array}{l}\text { - Questionários } \\
\text { - Reunióes }\end{array}$ \\
\hline AEX & Projeto & $\begin{array}{l}\text { - Contínua e com cobrança. } \\
\text { - Aspectos negativos e positivos do } \\
\text { projeto. }\end{array}$ & $\begin{array}{l}\text { - Redação } \\
\text { - Questionário }\end{array}$ \\
\hline
\end{tabular}

\section{Nos meandros da interdisciplinaridade, avaliaçáo e formaçáo pela/na extensão:discussóes e análises}

O Fórum de Pró-Reitores de extensão apresenta algumas diretrizes que orientam e sinalizam perspectivas epistemológicas que valorizam a diversidade, a pluralidade de ideias e, como consequência, as práticas educativas emancipatórias.

Encontramos em Santos $(2004 ; 2010)$ e Oliveira $(2008 ; 2010)$ os fundamentos para pensarmos na extensão como viabilizadora de práticas emancipatórias,uma vez que 
sinalizam possibilidades de pensarmos em epistemologias que contribuam com uma cidadania com vistas a uma justiça global, implicada com/na tessitura de diálogos entre conhecimentos plurais, que criem múltiplas racionalidades, ou seja, um projeto educativo emancipatório que problematize o conhecimento-regulação, típico da ciência cartesiana, pelo conhecimento-emancipação, transformando-se a solidariedade na forma hegemônica de saber e aceitando-se um certo caos (OLIVEIRA, 2010).

Assim, a interação dialógica; interdisciplinaridade e interprofissionalidade; indissociabilidade ensino-pesquisa-extensão; impacto na formação do aluno e impacto na transformação social (FORPROEX, 2013) são diretrizes que precisam ser significadas por meio da sistematização e da realização das açóes de extensão na tessitura do conhecimento, que se dá na relação dentro fora da Universidade.

A interdisciplinaridade, noção central na definição do conceito de extensão definida pelo FORPROEX (2013), precisa ser discutida, entendida e concretamente realizada nas açóes de extensão realizadas no âmbito das IES, uma vez que o paradigma da fragmentação não contribui com a visão de totalidade e de complexidade inerente ao mundo, àspráticas cotidianas. A interdisciplinaridade promove a interação no campo da ciência, associando o que se ensina aprende às condiçóes concretas da vida, de maneira a atribuir sentido e uma maior aproximação da realidade vividasentida.

Assim, adentramos na imbricada relação entre epistemologia e pedagogia, que nos dizeres de Pavianni(apud LÜCK, 2007, p. 53), "há que se superar a mentalidade que separa e esconde as relaçóes entre a situação pedagógica e a situação epistemológica, isto é, entre o ensinar e a produção de conhecimentos científicos”.

Para Goldman (1979, p. 3-25), "um olhar interdisciplinar sobre a realidade permite que entendamos melhor a relação entre seu todo e as partes que a constituem, superando a visão de fragmentação da ciência positivista". No entanto, o radical "disciplina" permanece, o que nos faz pensar qual o espaço, nessa definição, para o diálogo com o senso comum, com os saberes do cotidiano.

$\mathrm{Na}$ perspectiva do Fórum, a interdisciplinaridade parece apresentar um outro entendimento, quando propóe o diálogo simultâneo entre educação-cultura-científico e político. Em Câmara (apud REIS, 2009, p.15), encontramos a seguinte definição de interdisciplinaridade:

A interdisciplinaridade deve ser pensada como entre ciências, por um lado, considerando o território de cada uma delas e, ao mesmo tempo, identificando possíveis áreas que possam se entrecruzar, buscando as conexóes possíveis. $\mathrm{E}$ essa busca se realiza por meio de um processo dialógico que permite novas interpretaçóes, mudança de visão, avaliação crítica de pressupostos, um aprender com o outro, uma nova reorganizaçáo do pensar e do fazer.

Pensamos que ensino-pesquisa-extensão, entendidos em uma trama, em uma relação formativa, não pode abrir mão de saberes fazeres que dialogam com epistemologias plurais, emancipacionistas. Encontramos essas perspectivas na tessitura de açóes que expressam a relação da extensão com o ensino e a pesquisa, através de ideias como:

Vivência das práticas de pesquisa, ensino e trabalho por parte do grupo que compóe o projeto, com membros da sociedade, produz um aprendizado prático para a vida estudantil; a prática como fortalecedora dos conceitos estudados em sala de aula (AE VII - PROJETO/UERN, 2016). 
Extensão como campo de pesquisa fomentadora de mudanças nos cenários de formação das instituições envolvidas (AE II - PROJETO/UERN,2016).

Entendemos, como Fazenda (2013), que o diálogo é a única condição possível para um fazer interdisciplinar. Nesse sentido, acreditamos ser necessário ampliar discussóes que possam viabilizar ressignificaçóes de sentidos que expressam a extensão como momento de aplicaçáo da teoria, do conhecimento científico aprendido na universidade. Essas visóes ainda se sustentam em paradigmas da fragmentação e na ideia de que é possível alijar saberes outros, quando diferentes do conhecimento dogmático da ciência moderna. Percebemos essa perspectiva em expressóes como:

A relação ensino, pesquisa e extensão ocorre através da vivência da equipe de trabalho na aplicação prática das teorias estudadas em sala de aula, junto aos participantes (AE VIII - CURSO/UERN, 2016).

Pesquisa: o aluno deve realizar pesquisas sobre assuntos relacionados ao conteúdo do curso;

Ensino: necessidade de o aluno aprender e aprofundar conteúdos do Curso; Extensão: momento de compartilhar o conhecimento adquirido na graduação (AEI - CURSO/UERN, 2016).

Acreditamos ser necessária a ampliação da discussão dos conhecimentos sobre a natureza da extensáo, a fim de nos afastarmos de perspectivas que se sustentam na ideia de aplicabilidade dos conhecimentos acadêmico-científicos junto à comunidade. As perspectivas epistemológicas quese aproximamda natureza de uma extensão dialógica e interdisciplinarpreconizam a ideia de reciprocidade e mutualidade frente ao conhecimento tecido dessa/nessa relação - universidade/sociedade. Assim, a ação extensionista se concretiza em um fazer junto coma comunidade, em que ambas participam com seus saberes e se transformam mutuamente.

A interdisciplinaridade enquanto perspectiva epistemológica e atitude pedagógica se pauta em um diálogo plural entre os saberes da ciência e os saberes do cotidiano, o que nos faz pensar se a perspectiva epistemológica multirreferencial (ARDOINO, 1998) não seria mais adequada para pensarmos em um conceito de extensão que extrapole o radical disciplinar e caminhe em uma perspectiva de valorização de saberes plurais, das diferenças e do exercício da práxis, percebendo, inclusive, a complexidade dos fenômenos formativos que ocorrem na relação universidade/sociedade.

As açôes de extensão aprovadas no Edital de carga horária/2016 nos fizeram pensar que os projetos de extensão, pela sua área de atuação, podem apresentar diferentes níveis de interdisciplinaridade, desde o mais simples ao mais complexo, ou seja,um projeto de atendimento odontológico à comunidade se diferencia de um projeto com leituras dialogadas junto à comunidade. $\mathrm{O}$ primeiro se caracteriza mais como uma prestação de serviço, e o segundo possibilita a dialogicidade por meio do diálogo de saberes plurais, tendo por natureza uma atitude pedagógica mais interdisciplinar. Assim, percebemos que alguns projetos pensam essa relação de diferentes formas:

A pesquisa comparece de modo indireto (pesquisa bibliográfica como campo de análise contínuo, importante para lidar com o ensino necessário nas açôes do projeto); a extensáo gera discussôes sobre o tema que requer constante atualização (AE IX - PROJETO/UERN, 2016). 
Nesse projeto, percebemos que a fonte retroalimentadora do ensino e da pesquisa não é o diálogo com a comunidade, mas os casos específicos de tratamento odontológico que geram a necessidade de estudos e discussão na sala de aula,caracterizando-se como uma prestação de serviço na comunidade.

É fato que o debate continuado na formação sobre a Universidade que temos e a Universidade que queremos requer pensar a extensáo como espaço tempo de tessitura epistemológica, que ressignifica o ensino e a pesquisa,sinalizando a necessidade de epistemologias e metodologias dialógicas, interdisciplinares e fomentadoras de uma formação emancipatória, só possível de se concretizar em um diálogo consigo, com o outro e com o mundo. Nessa formaçáo, o conhecimento científico se hibridiza a tantos outros saberes, tornando possível a inteligibilidade das tantas práticas cotidianas muitas vezes "silenciadas".

No que diz respeito à avaliaçáo, não nos deteremos nos aspectos e discussóes mais amplas que perpassam a educação e outras áreas, no entanto, analisaremos alguns recortes feitos na escrita das ações em torno da avaliação pretendida e sua relação com a retroalimentação entre o contexto acadêmico e sua inserçáo social, a partir do que se pretende atingir.

Assim, discorrer sobre avaliação faz com que percebamos a capacidade de ir e vir no direcionamento da revisão e revitalização das açóes realizadas pelos envolvidos nessas ações.Dessa forma, remontamo-nos à avaliação como um processo que esteja em articulação permanente entre os avaliados e avaliadores, sendo assim democrática, clara e perceptível, com a intenção de melhoria dos aspectos avaliados.

Entendemos ainda que não existe um formato de avaliação, justamente pela diversidade dos participantes e das açóes, como confirma Dias Sobrinho (2002, p.40): "não há um modelo único de avaliação, uma só concepção, uma só prática. Falar de avaliação é necessariamente tratar de avaliaçóes. Plurais, mas não aleatórias, descomprometidas, devem ser confiáveis e justas, técnica e eticamente".

A avaliação em si é modificadora dos agentes e só terá sentido, via seus instrumentos, se for capaz de conduzir quem avalia para tomadas de decisóes que tomem por base a melhoria do contexto analisado.Nesse sentido, os instrumentos avaliadores devem contemplar as especificidades das açóes apresentadas, a partir dos objetivos apresentados inicialmente, e, por isso, se diferenciam de ação a ação.

$\mathrm{Na}$ extensão, o processo avaliativo deve atingir a comunidade acadêmica e os agentes sociais envolvidos, pois são partícipes reais e capazes de perceberem as mudanças efetivas realizadas em seus contextos.

No documento da Política Nacional de Extensão Universitária (BRASIL, p.88), temos:

Ainda no que se refere à avaliação, cabe ressaltar que a Extensão Universitária deve ser entendida como processo formativo, prospectivo, quantitativo e qualitativo, a ser mensurado por critérios objetivos (relatório, trabalho escrito, publicação ou comunicação) e subjetivos (compromisso, dedicação). Esse processo deve estar integrado à avaliação dos objetivos e metas dos programas ou projetos extensionistas, assim como à avaliação dos critérios da participação do estudante - e da equipe de trabalho na qual este se inclui - sobre os problemas sociais. 
Vemos então como a avaliação entendida no documento nacional comunga com nossa ideia de que a avaliação acontece entrelaçada de vários critérios que se adequam ao projeto, programa ou cursos extensionistas.

Pensar assim também nos faz refletir sobre as metas e os objetivos a serem inicialmente descritos em qualquer ação de extensão, tendo em vista que, no próprio formulário preenchido por quem propõe a ação, esse é um dos requisitos necessários.

Entendemos que a avaliaçáo deve estar consoante, coerente com todo o projeto e principalmente com a contemplaçáo das metas delineadas para serem atingidas a partir dos objetivos propostos.

Pois bem, diante desta reflexão e entendimento, colocamos a análise de nossas açóes em torno do aspecto avaliativo apresentado e seus instrumentos.Iniciamos com uma indagaçáo que consideramos significativa no processo de avaliação: ao avaliarmos, náo devemos direcionar para nossas metas pretendidas e alcançadas ou não, em funçáo dos objetivos propostos nas açóes de extensão? Será que propomos avaliaçôes em função de uma exigência imposta pelo programa de extensão, em que devemos cadastrar nosso curso, projeto ou programa? Para quê e para quem, de fato, avaliamos?

Nesse direcionamento, e a partir do corpus avaliado, percebemos o quanto evasivo é o norteamento da avaliação descrita nas ações de extensão, utilizando chavôes como: compreender como o público vê esse projeto, sem a preocupação de quais metas e objetivos atingidos até entáo. Das 10 propostas analisadas, apenas uma se refere aos objetivos das açōes, quando na avaliação retrata o seu direcionamento para: "verificação dos objetivos atingidos", no entanto, não especifica como fará isso, o que fará com essa verificação, nem para quêe para quem a avaliação será efetivada.

Parece-nos, então, que o processo avaliativo não é relevante, nem nos mostrará a relevância ou não da ação perante à sociedade, e esse pode ser um embate muito maior na política de inserção social, pois ouvir os atores sociais das açôes extensionistas fará com que a universidade seja revista e ampliada a partir dos que estão fora dela,fazendo-se reflexôes e leituras que extrapolam os seus muros, consolidando, portanto, a articulaçáo entre academia e sociedade.

Também nos parece que as avaliaçóes propostas, com seus instrumentos vagos e imprecisos - como reunião, relatórios, artigos -, faz-nos perceber que o preenchimento do formulário induz a uma proposta avaliativa que náo reflete a realidade inserida no contexto maior das açóes apresentadas, mas sinaliza uma intenção democrática do processo avaliativo em si, e por isso capaz de promover alteraçóes e ampliaçóes em seu contexto.

Nessa mesma perspectiva, encontramos o questionário como instrumento avaliativo em 9 das 10 propostas de ação escolhidas para análise.

Os questionários são instrumentosque, como outros instrumentos de avaliação, não possibilitam por si só refletir toda a realidade apresentada, no entanto, parece ser um instrumento simples e conhecido por todos e, por isso, citado em todas as propostas extensionistas analisadas.

Todo instrumento de avaliaçáo precisa ser claro e o mais preciso possível, para que possibilite uma leitura da realidade vivida não só aos que estão à frente das açôes, mas também pelos protagonistas que delas fizeram parte.Mesmo assim, um discurso comum a quase todos os projetos avaliados foi a busca pela melhoria das açóes, o que alicerça ainda 
mais a análise inicial de que, nos discursos, são utilizados chavóes incorporados em nosso cotidiano, haja vista a falta de especificação e vinculação das açóes aos objetivos descritos.

Dessa feita, chegamos a refletir sobre a questão para quê e para quem avaliamos? Percebemos que náo se sabe bem para quê avaliamos, tendo em vista não nos dirigirmos a nenhum objetivo nem meta dos projetos, no entanto, para quem avaliamos, ou melhor, direcionamos nossa avaliação, podemos perceber - pelo discurso pouco fundamentado e de relaçáo com as açóes de extensão - que propomos avaliaçáo para que se constituam como documentos legais exigidos pela instituição.

Não queremos dizer aqui que nossas ações de extensão estão fora do contexto social em que se inserem, nem do contexto acadêmico em que se enquadram e dão origem, mas que necessitamos urgentemente, nós todos, a Pró-Reitoria de Extensão e os que fazem e coordenam as propostas extensionistas, refletir sobre o que de fato devemos avaliar, tendo em vista nosso intuito maior que é fazer com que os objetivos de cada proposta sejam contemplados.

De nada adianta haver uma proposta a ser realizada se não a analisamos e pensamos em como os sujeitos partícipes da proposta pensam e analisam, a partir da sua realidade social e sua inserção nas ações executadas.

Ter voz e vez na análise das açóes de que participamos é fundamental para a sua melhoria e, principalmente, para o envolvimento e corresponsabilidade da comunidade acadêmica e da sociedade, na tentativa de entrelaçarmos os saberes/fazeres táo úteis e necessários à universidade, muitas vezes distante dos seus além muros.

\section{Conclusóes: o caminho ressignificado}

A prática de atividade de extensão no âmbito da Universidade do Estado do Rio Grande do Norte vem sendo gradativamente qualificada em função de um olhar sistematizado e preocupado da Pró-Reitoria de Extensão, que chama a comunidade acadêmica para um processo continuado de discussão conceitual, epistemológica, metodológica e política.

É nesse cenário de desejo de ampliar e melhorar a qualidade das atividades de extensão que este artigo foi produzido, sinalizando, inclusive, perspectivas formativas que possibilitem a ressignificação da sistematização e da realização das açóes de extensão, viabilizando o que preconiza aPolítica Nacional de Extensão. Este estudo desvelou,no entanto, que se faz necessário um processo formativo junto àComissão de Extensãocolegiado consultivo, deliberativo e responsável pela avaliação e aprovação das açóes de extensão -,a fim de melhorar os processos de avaliação e de orientação na elaboração e realização das atividades de extensão, considerando os seguintes pontos, a saber:

- Qual o sentido atribuído à natureza do conceito de extensão no âmbito da UERN;

- O que caracteriza de fato uma ação extensionista;

- Como percebemos a relação entre ensino-pesquisa-extensão;

- A interdisciplinaridade está sendo viabilizada nas ações de extensão e como a compreendemos.

- Quais públicos, quais epistemologias e quais avaliaçóes precisam fazer parte da natureza da extensão na Universidade. 
As ações avaliadas reforçam ainda mais a importância da extensão para a qualidade da formação acadêmico-profissional-humana. Um aluno e um docente que vivenciam uma experiência aprendente junto com a comunidade é alguém possível de se abrir para conhecimentos plurais, de ser criativo, de se perceber parte de uma totalidade que só faz sentido quando tecida por/em redes de conhecimento,na relação dentro fora da Universidade.

Por fim, concluímos que a extensão precisa ser continuamente qualificada como uma formação em devir, uma política de sentido, cujo horizonte é a formação emancipatória e implicada consigo, com o outro e com o mundo.

\section{Referências}

OLIVEIRA, Inês Barbosa. Currículos praticados em tempos de globalização: o cotidiano escolar e seus condicionantes na criação de alternativas emancipatórias. In: (Org.). Práticas cotidianas e emancipação social: do invisível ao possível. Petrópolis, RJ: DP et al., 2010.

ALVES, Nilda.Decifrando o pergaminho oscotidianosdasescolasnaslógicasdas redescotidianas.In: ALVES, Nilda;OLIVEIRA,InêsBarbosa(Orgs.).Pesquisa nos/dos/com os cotidianos das escolas. 3. ed. Petrópolis: DP\&A, 2008.

ARDOINO, Jacques. Abordagem multirreferencial (plural) das situações educativas e formativas. In: BARBOSA, J. (Org.). Multirreferencialidade nas ciências e na educação. São Carlos: EDUFScar, 1998.

CERTEAU, Michel de. A invenção do cotidiano: artes de fazer. 19. ed. Tradução de Ephraim Ferreira Alves.Petrópolis, RJ:Vozes, 2012.

FAZENDA, Ivani C. A. Práticas interdisciplinares na escola. 13. ed. São Paulo: Cortez, 2013.

FREIRE, Paulo. Pedagogia da autonomia: saberes necessários à prática educativa. São Paulo: Paz e Terra, 1998.

JOSSO. Marie-Christine. Experiências de vida e formação. Tradução de José Claudio e Júlia Ferreira. Natal, RN: Edufrn; São Paulo: Paulus, 2010.

LÜCK, Heloísa. Pedagogia Interdisciplinar: fundamentos teórico-metodológicos. 14. ed. Petrópolis, RJ: Vozes, 2007.

MACEDO, Roberto Sidnei. Outras luzes: um rigor intercrítico para uma etno pesquisa política. In: MACEDO, Roberto Sidnei; GALEFFI, Dante; PIMENTE Álamo. Um rigor outro: sobre a questão de qualidade na pesquisa qualitativa. Salvador: Edufba, 2009, p. 75-126.

. Compreender/mediar: o fundante da educação. Brasília: Liber livro, 2010.

OLIVEIRA, Inês Barbosa. Boaventura e a educação. Belo Horizonte: Autêntica, 2008. 
POLÍTICA NACIONAL DE EXTENSÃO UNIVERSITÁRIA. Fórum de Pró-Reitores de Extensão das Instituições Públicas de Educação Superior Brasileiras. FORPROEX, Porto Alegre. 2a imp., ago.2013.

REIS, Marlene Barbosa de Freitas. Interdisciplinaridade na prática pedagógica: um desafio possível. Revista de educação, linguagem e literatura da UEG, Inhumas, v. 1, n.2, out. 2009. Disponível em: http:// pt.slideshare.net/edselma/texto-interdisciplinaridade-napraticapedagogica Acesso em: 03 mar. 2016.

RIBEIRO. Mayra R. Fernandes. A sala de aula no contexto da cibercultura: formação docente e discente em atos de currículo. 207 f. 2015.Tese (Doutorado) - Universidade do Estado do Rio de Janeiro, UERJ,Rio de Janeiro, 2015.

SANTOS. Boaventura de Sousa. Conhecimento prudente para uma vida decente: um discurso sobre as ciências revisitado. São Paulo: Cortez, 2004.

. Para além do Pensamento Abissal: das linhas globais a uma ecologia de saberes. In: SANTOS, Boaventura de Sousa; MENESES, Maria Paula. Epistemologias do Sul. Lisboa: Almedina, 2010. 